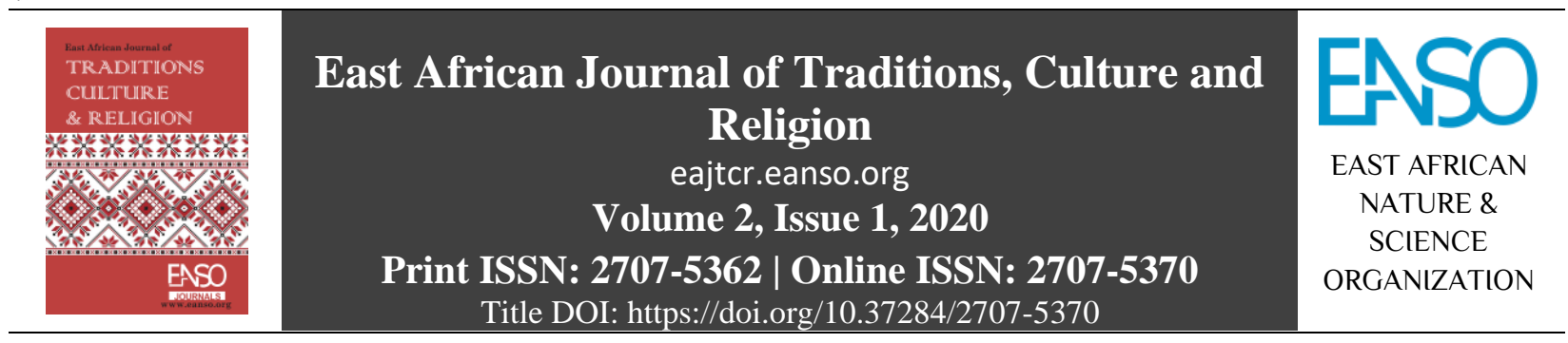

Original Article

\title{
Psychology of Perverse Sexual Behaviour: Socio-Psychological Crisis in Kenya
}

\author{
Bernard Sorre, PhD $D^{1}$, Peter Oino, $P h D^{2} \&$ Nancy Cheseto, $P h D^{3 *}$ \\ ${ }^{1}$ Department of Anthropology \& Human Ecology, Moi University, P.O. Box, 3900 - 30100, Eldoret, Kenya. \\ ${ }^{2}$ Department of Peace, Security \& Social Studies, Egerton University, P.O. Box 536 - 20115, Egerton, Kenya. \\ ${ }^{3}$ Mount Kenya University, P. O. Box 342 - 01000, Thika, Kenya. \\ ${ }^{*}$ Correspondence Email: ncheseto@mku.ac.ke \\ * ORCID: https://orcid.org/0000-0002-7013-320X
}

Article DOI: https://doi.org/10.37284/eajtcr.2.1.197

Date Published:

26 August 2020

Keywords:

Psychology,

Perverse Sexual

Behaviour,

Socio-Psychological

Crisis.

\section{ABSTRACT}

One of the greatest social crises in the world today is sexuality. Kenya is one of the developing countries whose social and economic institutions have been adversely affected by sexual perversions. The media, religion, academic, police and legal reports indicate shocking revelations about the extent to which sexual perversions have engulfed Kenyans. Rape, bestiality, paedophilia, incest, sexoriented violence and insults characterize the social landscape of the country with dire implications on the family, health, religious, economic, political and other vital institutions of the society are ever reported. Cases of priests/pastors/imam defiling their 'flock'; teachers sexually assaulting their students; prostitution and promiscuity; fathers raping their daughters; jobs being awarded on sexual advances are not uncommon. Consequently, people are dying of sexually-oriented diseases; hospitals are full of sex health problems; families are breaking because of sex and sex-related challenges; streets are full of abandoned children; leaders have lost to their enemies because of sex; companies have been rundown because of sex; professionalism has waned because sex has replaced merit; students are passing examinations because of sexually transmitted marks; the environment is polluted because of sex; even religious books warn that many may miss the Kingdom of God because of sexrelated sins. Sex sin is everywhere. It is not limited to the bedroom anymore, but to the television, movies, billboards, office buildings, hotels, kitchen, cars, classrooms, in the field, corridors, in conferences, toilets, churches, mosques, streets, and in the bush, just to name a few of the spaces. This paper provides some empirical and conceptual observations, which suggests 'a sex crisis' that is reflected in the kind of sexual patterns observed in the Kenyan society today. The current social and moral policies emphasize equity, human rights and freedom. However, there is a lack of or little on self-control and morality 
mechanisms in social control systems especially in relation to rapid sociocultural changes that have led to identity and personality crisis. This has led to the prevalence of sexual patterns that advance egocentrism rather than the common good. Consequently, the paper recommends a reflection on what actually happened to the sex moral values in Kenya and suggests what the society's leadership should do to inform policy-oriented strategies that can tame the current situation.

\section{APA CITATION}

Sorre, B., Oino, P., \& Cheseto, N. (2020). Psychology of Perverse Sexual Behaviour: Socio-Psychological Crisis in Kenya. East African Journal of Traditions, Culture and Religion, 2(1), 39-47. https://doi.org/10.37284/eajtcr.2.1.197

\section{CHICAGO CITATION}

Sorre, Bernard, Peter Oino, and Nancy Cheseto. 2020. "Psychology of Perverse Sexual Behaviour: Socio-Psychological Crisis in Kenya". East African Journal of Traditions, Culture and Religion 2 (1), 39-47. https://doi.org/10.37284/eajtcr.2.1.197.

\section{HARVARD CITATION}

Sorre, B., Oino, P. and Cheseto, N. (2020) "Psychology of Perverse Sexual Behaviour: Socio-Psychological Crisis in Kenya", East African Journal of Traditions, Culture and Religion, 2(1), pp. 39-47. doi: 10.37284/eajtcr.2.1.197.

\section{IEEE CITATION}

B. Sorre, P. Oino, and N. Cheseto, "Psychology of Perverse Sexual Behaviour: Socio-Psychological Crisis in Kenya", EAJTCR, vol. 2, no. 1, pp. 39-47, Aug. 2020.

\section{MLA CITATION}

Sorre, Bernard, Peter Oino, and Nancy Cheseto. "Psychology of Perverse Sexual Behaviour: Socio-Psychological Crisis in Kenya". East African Journal of Traditions, Culture and Religion, Vol. 2, no. 1, August 2020, pp. 39-47, doi:10.37284/eajtcr.2.1.197.

\section{INTRODUCTION}

In the African tradition, sex and sex-related issues have for a long time been regarded as an adult affair and handled with severe caution on confidentiality, anonymity, and secrecy. However, with the rapid socio-economic and political changes taking place in the world; the process of globalization and global integration; multicultural and multinational contacts, sexual attitudes have changed in the last 50 years. In fact, not so much sexual behaviour, but society's attitude towards it has changed. This is why there is a strong sexual movement in the name of rights, recognition and legal debates for sexual behaviour that were traditionally prohibited and presumed abnormal.

Historically, it was until after World War II and in the 1950s that sexual behaviours were a taboo and subject to open discussion. Sex was conducted behind closed doors and in the confined to marriage. Consequently, in the 1960 s sexual attitudes undoubtedly became more permissive and brought openly-declared attitudes in line with the realities of sexual behaviours. Social movements challenged the existing order of society; this was evidenced by the decay of existing sexual norms, free love and pre-marital sex, which have been adopted in modern times. In America for instance, in the 1970s, New York's Gay Activist Alliance (GAA) was the leading radical gay organization. A year or two earlier, the Gay Liberation Front (GLF) became the most vocal organization and sponsored the first Gay Liberation March (not parade) in the city. However, GLF broke up rather quickly due to internecine warfare about their goals and was replaced by GAA that devoted itself to fight only for gay rights (Kimmel \& Lesniak, 2011).

It is argued that a person liable to sexual perversions is fully preoccupied with thoughts of goal achievement, forgetting about moral behaviours and possible responsibility before the law. All other kinds of sexual activity lose any sense for him/her. For instance, homosexuality is not a recent phenomenon, four decades ago, Weinberg and Williams (1974) did a study on homosexuality in America and found three characteristics among individuals regarded as gay 
men. First, they rejected the idea that homosexuality was an illness; they had close and supportive associations with other gay people, and they were not interested in changing their homosexuality. According to Kimmel (2011), for one to pursue this life [gayism], he has to develop the internal sense that "it's normal for me" in spite of the bigoted attitudes of others... and "serendipity," the opportunity [other gay mentors] that emerges and yields significant benefits.

When Sigmund Freud in 1896 in (Holland, 1990) postulated the psychoanalytic theory and claimed that human nature is influenced by sex instinct, there were so many reactions to his ideas that many people thought he was immoral and crazy. In this society, men and women are consistently preoccupied with sex instinct and have gone lose to engage in sexual activities in disregard of the moral values that surround sexuality in African society.

This paper seeks to explain the phenomenon of sexual perversion as a moral issue in our society. The author begins with a section on the foundation of sex and sexuality issues as part and parcel of human nature, but closely guarded by normative sentiments that are based on the people's cognitive behaviour. Sex is, therefore, sanctioned, approved but also, guarded by religious teachings, human dignity, and societal norms and values. In the subsequent sections, the authors delve into sexual crisis brought about by rapid changes in the Kenyan society.

\section{FOUNDATIONS OF SEX AND SEXUALITY IN HUMANITY}

From a theological perspective, the Biblical book of Genesis Chapter One presents the story of the creation of the world by God. That, man, was created in God's own image. God further saw that man was lonely and so created the woman out of man's flesh. This saw the theological origin of sex and sexuality in humanity. From this moment, the subsequent stories are about the fall of man from God's love into sin. Adam and Eve engaged in a sexual relationship that condemned them into a life punishment for them and their future generations from God (Genesis: Chapter One). Throughout the Holy Bible, especially the Old Testament into the New Testament, there is a consistent illustration of sex-oriented sins, evils, condemnations, and redemption of humankind with the coming of Jesus Christ.

The theological origin of human sexuality presents a divine intention to create sex, which is good for humanity but was mismanaged by human greed, lust and desires. According to the Book of Genesis $2: 24$, "Therefore, a man should leave his father and mother, and shall cleave unto his wife: and they shall be one flesh." This is the deepest physical and spiritual unity of man and woman and holds up monogamy restricting sexual activities to only one spouse, before the world as a form of marriage ordained by God. Consequently, various sexual relationships were also prohibited. For instance, adultery (Exodus 20: 14), incest (Leviticus 18: 617), prostitution (Leviticus 21: 7), rape (Deuteronomy 22: 28-29), bestiality (Leviticus 18: 23), homosexuality (Leviticus 18: 22) and polygamy (Leviticus 18: 18).

From the genetic/biological point of view, in sexually reproducing organisms, no domain is more closely linked with the engine of the evolutionary process than sexuality (Buss, 1998). Men and women across human evolutionary history have confronted different adaptive problems in the sexual domain. This biological perspective was influenced by the works of Charles Darwin (1859:1) who argued that:

\section{Because reproduction is central to the evolutionary process, domains closely linked with reproduction should be the focal target of selection processes and hence, loci for evolved mechanism or adaptation. No domain is close to reproduction than sexuality...}

These ideas offer an account of sexuality-related adaptive problems and present a view of human sexual psychology as a rich repertoire of mechanisms that have evolved as adaptive solutions. A host of specific predictions about human sexuality follows from this analysis including an account of sex differences in the desire for sexual variety, the qualities preferred in shortterm and long-term mates, context-dependent shifts in mate preferences, the nature of sexual jealousy, the tactics that are effective for attracting and retaining a mate, and the causes of sexual conflict between men and women (Buss, 1998). 
These two main perspectives, theological and biological have influenced the interest in studying and controlling humankind's most basic drive, sex. From a chronological point of view, the desire to break that traditional silence about sex in human societies has been influenced by the crises that the world has been facing over time. In the 1830s, the focus was on the issues of "self-pollution" characterized by the immense masturbation, which was responsible for everything from warts and constipation to insanity and death (Cornblatt, 2009). Health reformers in the 19th century in America, associated bodily discipline with ideal manhood and used sex education manuals to propagate that message.

The rapid urbanization of the late 1800s and early 1900s was accompanied by an increased interest in organized sex education. As people in America, Europe and other developed societies moved from farms where children might politely observe the mating of the family livestock to cities rife with temptation, public officials began to see a greater need for classroom instruction about the facts of life. In America, the National Education Association first discussed the subject in 1892, passing a resolution that called for "moral education in the schools" (Cornblatt, 2009).

In 1913, Chicago became the first major city to implement sex education for high schools. Later on, it took rampant Sexually Transmitted Diseases (STDs) during World War I (WWI) to get the federal government involved in sex education (Cornblatt, 2009). In 1918, Congress passed The Chamberlain-Kahn Act, which allocated money to educate soldiers about syphilis and gonorrhoea (Cornblatt, 2009). During this time, Americans began to view sex education as a public health issue. The earliest sex-education film, Damaged Goods, warned soldiers of the consequences of syphilis. In the film, a man had sex with a prostitute the night before his wedding, gets syphilis, passes the disease on to his new-born baby, and then commits suicide. When the HIV and AIDS scourge emerged in the early 1980s, proponents of sex education found their position strengthened. By the mid-1990s, every state had passed mandates for HIV and AIDS education, sometimes tied to general sex education and sometimes, not (Cornblatt, 2009).
Outside of Western Europe and the United States, sex education remained largely informal until concerns of population explosion and the HIV/AIDS crisis prompted international organizations such as the United Nations to become involved in educating residents in Africa and South Asia particularly, about contraception and prophylaxis (Angelo, 2003). Although the existence of religious opposition has been muted, educators have often been met with resistance from some governments unwilling to admit that their populations were experiencing problems related to HIV and AIDS and from male traditionalists, reluctant to allow women greater control over their sexuality (Angelo, 2003).

Some studies conducted, for example, Haselton and Gangestad (2006), as well as Maner et al. (2008), indicate how an array of factors among individuals display relationship maintenance biases. For example, the likelihood of infidelity is determined in part by the sexual attractiveness of one's current partner relative to alternatives. The reproductive benefits of staying committed to a long-term relationship partner may also depend on other factors such as the length of the relationship and whether or not the relationship has borne offspring. There are reproductive trade-offs associated with monogamy and mating decisions likely weigh both the costs and benefits associated with staying committed to a long-term monogamous relationship. Cognitive biases for relationship maintenance are displayed primarily when the benefits of maintaining the relationship outweigh the costs.

In Kenya, issues to do with sex and sexuality have raised heated debates among human rights activists and shocking revelations among the religious, moralists, politicians, the rural and urban segments of the population, and policy planners with dire consequences on the socio-economic development of the nation. The current state is that most Kenyans are witnessing various sex-related perversions that we are referring to as "sex crisis", which have been blamed for increasing cases of insult against minors and women, deaths of victims, HIV infections, sexoriented jobs, corruption, denial of rights and opportunities, breakdown of families, breakdown of the traditional values and morals on sex and 
sexuality, increased prostitution and promiscuity, and the moral decay in the society.

\section{SEX, SEXUALITY AND SEXUAL PERVERSION}

\section{Sex and Sexuality in the Kenyan-African Context}

Kenya is one of the African countries that boasts of a rich cultural orientation. The country has over 42 ethnic groups that have continued to experience and express a rich cultural heritage. In virtually all these ethnic groups, sex and sex-related issues are confined to the institution of marriage. Consequently, the sanctity of marriage as experienced in the traditional-customary setting is well defined and the place of sexuality is core because it is geared towards procreation and continuity of the society. However, in African societies, sex is not used for biological purposes alone. It also has religious and social uses. There are African people, for instance, the Akamba ethnic group, among whom rituals are solemnly opened or concluded with actual or symbolic sexual intercourse between husband and wife or other officiating persons (Mbiti, 1959). "This is like a solemn seal or signature in which sex is used in and as a sacred action, as a 'sacrament' signifying inward spiritual values” (Mbiti, 1959, p. 146).

Culturally, all human societies have norms and values that direct and control sexual acts among their members. To ensure the sustenance of this 'deified arena,' taboos are sounded and expressed to caution members. It does not give room for the situation we are facing today where sexual licentiousness is promoted and adorned with pride. In fact, sexual organs were considered a pathway to life in traditional societies. For instance, Mbiti strengthens the fact that sexual organs are the gates of life and for many African people, the genitals and buttocks are the parts of the body that must carefully be covered; the failure of covering them constitutes 'nakedness' in the eyes of traditional Africans (Mbiti, 1969). A phenomenon that is worth preserving today considering the influx of media appeals to the discomfort of seeing our women and young girls almost nude in the name of new-wave fashion.
Moreover, there was the procreative emphasis of sex in marriage itself, which the social structures of traditional African society, especially the family and community made adequate provision for. Consequently, the sexual deviation was indeed a threat to these structures. It became apparent that youth were to be trained for reproductive life in conformity to the structure through social initiation rites. Sexual morality was safeguarded by the societal structures more than by individual personal responsibility. Sexual activity was the subject of much ritual symbolism. It was frequently dramatized in dances and arts and was surrounded by many taboos, a typical example which was an avoidance relationship (Shorter, 1999; Okong'o, 2010).

Fornication, incest, rape, seduction, homosexual relations, incest, and sleeping with domestic animals, children watching the nakedness and genitals of the parents, all represented sexual felonies in a given community. Society deals differently with these felonies and African people are very sensitive to any deviation from the accepted norm concerning all aspects of sex. This is a fundamentally religious attitude since any felony upsets the smooth relationships of the community, which includes those who have already departed. For this reason, the offences must be followed by a cleansing ritual whether or not the offenders are physically punished, otherwise, misfortunes may ensue (Shorter, 1999).

Further, Kyalo (2012:217) observed that:

Be that as it may, virginity was held to be a good thing insofar as it is a promise of a harmonious marriage. If a girl is chaste before her wedding she will probably be faithful after it. Adultery is vicious because it not only steals the wife fertility but kills the marriage. The bride price does not buy a woman, but rather compensate her family for her fertility.

In general, Moler (1982) asserts that a man marries for life. Above all this applies to the first marriage; children cement the relationship, for their presence indicates that the contract has been fulfilled. I have continually contended that African traditional marriage system contained the proper ingredient to a healthy marriage. 
These ideas imply that Africans understood marriage and sexuality and had a way of upholding the richness of the value of marriage. When we talk of values in sex and sexuality we refer to interests, pleasures, likes, preferences, duties, morals, obligations, desires, wants, needs, aversions and attractions and many other modalities of selective orientation expressed by members of a given society in relation to how they sexually attract or respond (William, 1968).

\section{Sexual Perversion: The Emerging Trends in Kenya}

According to the American Academy of Clinical Sexologists (1929), sexual perversions are conditions in which sexual excitement or orgasm is associated with acts or imagery that are considered unusual within a particular culture. Perversion is present where the orgasm is reached with other normative sexual objects (homosexuality, paedophilia, bestiality, among others) or through other regions of the body (such as anal coitus), where the orgasm is subordinated absolutely to certain extrinsic conditions, which may even be sufficient in themselves to bring about sexual pleasure (fetishism, transvestitism, voyeurism and exhibitionism, Sado-masochism). According to Koenig (2012), sex perversion is a pretty good barometer of demonic activity and the moral state of society. Therefore, perversion implies the sumtotal of the psychosexual actions that are an adjunct to such non-conforming ways of obtaining sexual pleasure. People who are sexually pervasive tend to have their passion or sexual desire peak early in a relationship (Aron \& Aron, 1991; Berscheid, 1985). This is why for them; sexual desires do not express natural love that comes in a relationship; thus, their sexual orientation deviates from the societal expectations.

Sex and sex-related perversions are part and parcel of the day-to-day social facts and events in Kenya. Every new day comes with an emerging issue that depicts the society as both immoral and out of control. This is widely evident in media, police, and witness accounts of what actually takes place. Practical observation in the country has shown women and men [both married and unmarried] engaging in casual sexual activities with their bosses and juniors; lady students in schools, colleges and universities engaging in sexual activities with their male lecturers for marks; choirmasters dating their members; church leaders engaging in sexual activities with members of their "flock" including underage boys and girls; as maids continue to be sexually exploited by their male employers, and so on. In 2005, a lady student at Egerton University flogged her male lecturer for having had a sexual relationship with her and refusing to award her high marks in his course (Makabila, 2005).

Brothels and massage parlours are the order of the day in most affluent parts of the main towns in Kenya (Gitau, 2018). In fact, in a country where over $56 \%$ of its population is living in abject poverty, men and women are spending close to Ksh. 100,000 per night in exchange for sex. Reports and incidences of infidelity are like the order of the day. Just like politics, sex and sex-related perversions receive daily coverage in all the main newspapers with some like The Nairobian running weekly headings on matters of sexual perversions.

In Nairobi, taxi men are now lured into sex by their female clients as payment for the transport services offered, while prostitution and wife-swapping are common among the middle class and those with money. Cases of high-profiled personalities being found in sexually compromising situations and infidelity are not new. In fact, men and women are spending a lot of cash on exclusive sex dens in the city. Moreover, it is now women, who own the rooms and invite their men clients for sex at a fee (Sorre \& Oino, 2013).

In Mombasa, strip clubs in the larger north coast; brothels and massage parlours; open prostitution and promiscuity in the streets; sex-tourism; and pornographic shooting including human-animal movies are not new to the residents. The most recent case was when over ten university students were caught engaging in sexual acts with dogs at a fee in Nyali, while six other women were arraigned in a Kilifi court for striping in a club within Mtwapa area (Sorre \& Oino, 2013).

In central Kenya, cases of rape, incest and bestiality are reported on a daily basis. For instance, in the last week of June 2013, six cases of bestiality were reported in Kiambu County alone (Sorre \& Oino, 2013). Men being the main victims were found 
engaging in sexual acts with cows and sheep in particular. These are just some of the cases that are reported. During the same time in the same County, two men were jailed for defiling their own daughters (Sorre \& Oino, 2013).

Across the country, one of the most talked-about social issues of concern is the emerging sexual trends in Kenya. Men and women of the same sex have been witnessed seeking recognition from the government and their rights from the general public; other seeking legal redress to change their bisexual conditions, for instance, changing identity such as from Audrey to Andrew (Sorre \& Oino, 2013). This is motivated by the perceived setbacks for recognition, which Budge et al. (2008) and Lombardi et al. (2001) assert that transgender individuals experience extensive rejection and discrimination. For instance, the impact of male privilege for a female to males may be that the added discrimination and difficulty that male to females experience during their transitions indicate a more complex process for their coping and wellbeing; and it is also possible that the process is just as complex for FMT individuals (Budge, 2010). A study conducted by Budge et al (2010) indicated that there may be a moderating effect of assigned sex and facilitative coping with regard to levels of depression and anxiety. The genderqueer individuals who were assigned female sex at birth used more facilitative coping mechanisms as their anxiety and depression increased. However, this was not true for those who were assigned male sex at birth. Perhaps genderqueer individual's assigned female sex at birth were socialized to cope with depression and anxiety in a way that helps them deal with distress.

In the urban streets of Kenya, prostitutes have been demonstrating in major towns seeking recognition, fair treatment and rights of operation from the government and their clients. Prostitution is illegal in Kenya and commercial sex workers face arrest and dehumanized for their activities. This places the women at a severe paradoxical situation when dealing with their clients. Similar to the Kenyan commercial sex workers, O’Donnell et al. (2002:3) in his study in Binga Zimbabwe narrates that:

If a man refuses to pay after sex [as commonly occurs] then the commercial sex worker has no redress. More seriously, police are said not to be sympathetic towards cases of violence against commercial sex workers. The women report that beatings are practically a daily occurrence for them, yet if they report them to the police at best, they can receive a recommendation to seek treatment at the hospital, and at worst they can end up being fined or made to do community service.

All these are just indicators of some of the socialsexual revolutions taking place in Kenya. In fact, the cultural silence that existed about sex and sexrelated matters has been replaced by more vocal, open and exposed sexual scenes, uncensored materials, and public tolerance to the new habits.

Sexual perversions have been linked with the level of moral decay in the society and thus, when perversions are on the rise, the society, Kenyans in this case, are viewed as if they no longer care much about the sanctity of their bodies and uniquely human and sex as exclusive. Instead, men and women are out to explore their bodies sexually. The popular nude culture among urban men and women is a major moral issue of concern. In fact, nude and vulgar dances like strip and bend-over dances are the trend. Every Friday, The Standard newspaper, for instance, has a full-page under the Pulse pullout dedicate to "caught out through pulse lens". This page usually shows how men and women are publicly sexually-indulging. That is why the camera has captured and exposed them (Sorre \& Oino, 2013).

One may be tempted to think that sexual perversions are a preserve of the urban folks in Kenya; however, this is not true. The difference is actually in the types of perversion taking place in the two settings. For instance, cases of infidelity, incest, bestiality and adultery are largely associated with rural cases, while wife swapping, pornography, prostitution, brothels, massages, and sex for jobs is common in urban settings. In Nyanza, for instance, there have been reports of young men in villages competing to impregnate people's wives (Sorre and Akong'a, 2009). Various circumstances have been blamed for sexual perversion in Kenya. Sorre and Akong'a (2009) discussed power, status, access to resources, deprivation, psychological rewards, the culture of 
silence, weak social control, and socialization as the underlying reasons as to why sexual perversions are common in the Kenyan society.

\section{CONCLUSION}

The paper observes that sex crisis evident in the Kenyan society is detrimental to the future generations and socio-economic development of the nation. Therefore, we recommend that the society should invest in the restoration of the lost sex norms and values to save the nation from moral damnation and the spread of consequences of sexual perversion to other aspects of societal development.

\section{REFERENCES}

Angelo, V. (2003). HIV/AIDS, population and sustainable development. Cadernos de Estudos Africanos, (4), 99-120.

Aron, A., \& Aron, E. N., 1991. Love and sexuality. In K. McKinney \& S. Sprecher (Eds.), Sexuality in close relationships (pp. 25-48). Hillsdale, NJ: Erlbaum.

American Academy of Clinical Sexologists. 1929. 18th St., N.W., Suite 1166, Washington, DC 20009. (202) 462-2122.

Berscheid, E., 1985. Interpersonal attraction. In G. Lindzey \& E. Aronson (Eds.), Handbook of Social psychology (3rd ed., pp. 413-484). New York: Random House. Publishers.

Budge, S. L, Schneider, C., Rodriguez, A., KatzWise, S., Tebbe, E., \& Valdez, C., 2008. The Emotional roller coaster: Transgender experiences of positive and negative emotions. Poster presented at the Annual Meeting of the American Psychological Association, Boston, MA.

Budge, S. L., 2010. Well-being in the transition process: The role of loss, community, and Coping. Unpublished doctoral dissertation, University of Wisconsin-Madison.

Cornblatt, J. (2009, Oct 27). A Brief History of Sex $E d$ in America. Retrieved from Newsweek, available at https://www.newsweek.com/briefhistory-sex-ed-america-81001.

Gitau, E. (2018). The porn boom, and doom. Retrieved from SDE, available at https://www.sde.co.ke/pulse/article/20012354 21/the-porn-boom-and-doom.

Harley, D. A., Nowak, T. A., Gassaway, L. J., \& Savage, T. A. (2002). Lesbian, gay, bisexual, and transgender college students with disabilities: A look at multiple cultural minorities. Psychology in the Schools, 39, 525538.

Holland, N. N. (1990). Holland's Guide to Psychoanalytic Psychology and Literatureand-Psychology. Oxford University Press, New York.

Kimmel, D. C. (2011). Remarks on Receiving an Elder Award at the National Multicultural Conference and Summit, January 27, 2011, Division 44 Newsletter, Spring.

Kimmel, D. \& Lesniak C. (2011). Society for the Psychological Study of Lesbian, Gay, Bisexual, and Transgender Issues A Division of the American Psychological Association. Vol. 27, No.1 Spring.

Koenig, D., (2012). Society Is a Measure of Demonic Activity at http://www.virginiakapic.nl/patrimedia

Kyalo P. 2012. A Reflection on the African Traditional Values of Marriage and Sexuality International Journal of Academic Research in Progressive Education and Development, 1(2). 211-219.

Lombardi, E. L., Wilchins, R. A., Priesing, D., \& Moulof, D. (2001). Gender violence: Transgender experiences with violence and discrimination. Journal of Homosexuality, 42, 89-101.

Makabila, S. (2005, May 15). Kenya: Student Beats up Lecturer over Marks. Retrieved from All Africa, available at https://allafrica.com/stories/200505170139.ht $\mathrm{ml}$ 
Manera, J. K. Roubya, D. A. \& Gonzagab G. C. (2008). Evolution and Human Behavior 29 343-349.

Mbiti, J. S. (1999). African Religion and Philosophy. Nairobi: East African Educational

Moler, A. J. (1982). Love, Marriage and the Family: Yesterday and Today. New York: Alba House.

O’Donnell, M. Khozombah, M. \& Mudenda, S. (2003). The Livelihoods of Commercial Sex Workers in Binga, Save the Children.

Okong'o J. B. (2010). Embodiment in Luo Ohangla Performance: Mediating Identity through Music. LAP LAMBERT Academic Publishing.

Shorter, A. (1998). African Culture, an Overview. Nairobi: Pauline's Publications.

Silverstein, C. (2009). The implications of removing homosexuality from the DSM as a Mental Disorder. Archives of Sexual Behaviour, 38, 161-163.

Sorre, B. \& Akong'a, J., 2009. HIV/AIDs a psychosocial Problem in Africa. MAARIFA Journal, 3(1) 1-12. 